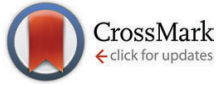

Cite this: J. Mater. Chem. B, 2015, 3, 7271

Received 22nd May 2015, Accepted 11th August 2015

DOI: $10.1039 / c 5 t b 00988 j$

www.rsc.org/MaterialsB

\title{
Oligoproline-derived nanocarrier for dual stimuli-responsive gene delivery $\dagger$
}

\author{
Mukesh K. Gupta, ${ }^{a}$ Sue Hyun Lee, ${ }^{a}$ Spencer W. Crowder, ${ }^{a}$ Xintong Wang, ${ }^{a}$ \\ Lucas H. Hofmeister, ${ }^{a}$ Christopher E. Nelson, ${ }^{a}$ Leon M. Bellan, ${ }^{\text {ab }}$ Craig L. Duvall ${ }^{a}$ \\ and Hak-Joon Sung*ac
}

\begin{abstract}
Gene therapy is a promising method for the treatment of vascular disease; however, successful strategies depend on the development of safe and effective delivery technologies with specific targeting to a diseased point of vasculature. Reactive oxygen species (ROS) are overproduced by vascular smooth muscle cells (VSMCs) at critical stages of atherosclerosis progression. Therefore, ROS were exploited as a stimulus for vascular targeted gene delivery in this study. A combination of bio-conjugation methods and controlled reverse addition-fragmentation chain-trasfer (RAFT) polymerization was utilized to synthesize a new ROScleavable, $\mathrm{pH}$-responsive $\mathrm{mPEG}_{113}-b-\mathrm{CP}_{5} \mathrm{~K}-b-\mathrm{PDMAEMA}_{42}-b-\mathrm{P}\left(\mathrm{DMAEMA}_{22}-\mathrm{CO}-\mathrm{BMA}_{40}-\mathrm{CO}-\mathrm{PAA}_{24}\right)(\mathrm{PPDDBP})$ polymer as a nanocarrier for plasmid DNA ( $p D N A)$ delivery. The ros degradability of PPDDBP polymers was confirmed by $\mathrm{SIN}-1$-mediated cleavage of $\mathrm{CP}_{5} \mathrm{~K}$ peptide linkers through a shift in GPC chromatogram with an appearance of mPEG shoulder peak and an increase in zeta potential ( $\zeta)$. The polyplex nanocarrier also demonstrated effective PDNA loading, serum stability, and hemocompatibility, indicating its excellent performance under physiological conditions. The polyplexes demonstrated ideal $\mathrm{pH}$ responsiveness for endosomal escape and effective ROS responsiveness for improved targeting in an in vitro model of pathogenic VSMCs in terms of both uptake and expression of reporter gene. These data suggest this novel nanocarrier polyplex system is a promising gene delivery tool for preventing or treating areas of high ROS, such as atherosclerotic lesions.
\end{abstract}

\section{Introduction}

Atherosclerosis is accompanied by progressive thickening of a vessel wall resulting from abnormal behavior of vascular cells in response to disturbed blood flow with inflammatory signals. Currently, to treat this disease it is common practice to reopen the blocked vessel with a stent; however, rapid re-occlusion (restenosis) occurs because the underlying problem of cell health is not addressed. Advances in vascular gene delivery over the past decade have demonstrated potential in addressing clinical issues that arise from restenosis by directly controlling the behaviors of the problematic cell types. ${ }^{1}$ To date, viral vectors are the most effective gene delivery platform due to their high transfection efficiency; however, safety issues such as immunogenicity and pathogenicity inhibit the broader clinical implementation of these systems. ${ }^{2,3}$ To address these issues, cationic polymers

\footnotetext{
${ }^{a}$ Biomedical Engineering, Vanderbilt University, Nashville, TN 37235, USA

${ }^{b}$ Mechanical Engineering, Vanderbilt University, Nashville, TN 37235, USA

${ }^{c}$ Division of Cardiovascular Medicine, Vanderbilt University, Nashville, TN 37235, USA. E-mail: hak-joon.sung@vanderbilt.edu

$\dagger$ Electronic supplementary information (ESI) available: Additional supporting figures. See DOI: 10.1039/c5tb00988j
}

and lipids have been explored as alternative delivery platforms due to their facile synthesis, tunable properties and demonstrated biosafety. ${ }^{4-6}$ However, low transfection efficiency in vascular cells (due to inefficient uptake) is considered to be a significant hurdle for clinical translation. ${ }^{7}$ In particular, none of the current gene delivery platforms demonstrated successful transfection into pathological vascular smooth muscle cells (VSMCs).

It is well known that overproduction of reactive oxygen species (ROS) is indicative of abnormal VSMC behavior, ${ }^{8,9}$ including the process of restenosis. ${ }^{10}$ However, the development of ROS-responsive polymeric nanocarriers that can target and deliver therapeutics into ROS-overproducing VSMCs is still quite limited. ${ }^{11}$ Recently, Xia et al. demonstrated an intracellular ROSdegradable cationic polymers containing thioketal units that effectively delivered plasmid DNA (pDNA) into cancer cells, suggesting that specific delivery to cells with high ROS is a feasible approach. ${ }^{12}$ Several previous studies demonstrated that polyplexes formed from pDNA and polycations have high transfection efficiency; ${ }^{13}$ however, low affinity of these polycations to pDNA can result in premature dissociation of polyplexes under physiological conditions. This problem can be overcome by an increased ratio of polycation to pDNA (N/P ratio), but at the expense of increased cellular toxicity. Therefore, the successful 
clinical application of cell-based gene therapy requires a stable, non-viral polyplex system that addresses both the extra- and intracellular environmental barriers without compromising biocompatibility.

Here, we report the successful utilization of PEGylated, oligoproline peptide-derived nanocarriers to improve pDNA transfection into VSMCs that are overproducing ROS due to inflammatory activation. ${ }^{14-16}$ Our nanocarrier is dual-responsive as it is programmed to react first to extracellular ROS, and then to intracellular $\mathrm{pH}$, imparting a specific functionality for application only in high ROS environments. ${ }^{12,17-19}$ Each copolymer block was designed to incorporate one or more desired properties, such as effective condensation with pDNA, serum stability, ROS degradability, $\mathrm{pH}$ responsiveness, hemocompability, cellular biocompatibility or improved transfection efficiency. This work represents a significant improvement over the current state-ofthe-art delivery methods. The extracellular ROS-cleavable, $\mathrm{pH}$ responsive polymer, $\mathrm{mPEG}_{113}-b-\mathrm{CP}_{5} \mathrm{~K}-b$-PDMAEMA $42-b-\mathrm{P}_{42} \mathrm{DMAEMA}_{22}-$ co- $\mathrm{BMA}_{40}-\mathrm{co}-\mathrm{PAA}_{24}$ ) (PPDDBP) was synthesized by combined approach of bio-conjugation methods and controlled reversible addition-fragmentation chain-transfer (RAFT) polymerization. The first block contains methoxy polyethylene glycol (mPEG) as a corona-forming hydrophilic block to shield the cationic poly(2-dimethylamino)ethyl methacrylate (PDMAEMA) block from nonspecific interactions with blood and tissue components until the polyplexes encounter a high ROS environment. ${ }^{20}$ Though PEG shielding of polyplexes is known to reduce the efficiency of cellular uptake ${ }^{21,22}$ and endosomal escape, ${ }^{23}$ pathophysiological stimuli, (including glutathione and MMPs) have been successfully employed for targeted dePEGylation of cationic polyplex to rescue drug and gene delivery capabilities. ${ }^{20,21,24}$

To induce dePEGylation under high ROS environments, a proline oligomer, cysteine-(proline) $)_{5}$-lysine $\left(\mathrm{CP}_{5} \mathrm{~K}\right)$ peptide was chosen as an ROS degradable second block, based on our previous work. $^{25-27}$ The third block, hydrophilic PDMAEMA contains positively charged tertiary amines, which facilitate effective condensation of nucleic acids through interaction with negatively-charged phosphate groups. ${ }^{28}$ The fourth block, a core-stabilizing hydrophobic terpolymer P(DMAEMA-co-BMAco-PAA) is composed of $N, N$-dimethylaminoethyl methacrylate (DMAEMA), $N$-butyl methacrylate (BMA), and 2-propylacrylic acid (PAA). This terpolymer block is ampholytic in nature under physiological $\mathrm{pH}$ with approximately equimolar ratios of positively charged DMAEMA and negatively charged PAA, together with hydrophobic butyl methacrylate (BMA). ${ }^{29,30}$ The low $\mathrm{pH}$ within the endosome triggers protonation of the negatively-charged PAA with a simultaneous increase in the positive charge of the DMAEMA. This increased positive charge destabilizes the polyplex core and causes membrane disruption, thereby enabling endosomal escape of the nanocarrier. ${ }^{21,31,32}$ As a control, we used a non-ROS-cleavable polymer without the $\mathrm{CP}_{5} \mathrm{~K}$ peptide to demonstrate enhanced uptake of these polyplexes under ROS rich environments.

The polyplex nanocarrier was evaluated for its size, charge, morphology, ROS degradability, pDNA condensation, serum stability and blood compatibility. To demonstrate the feasibility of ROS-responsive gene delivery into pathogenic VSMCs, we additionally investigated cellular uptake, cytotoxicity, and in vitro transfection efficiency with human coronary artery smooth muscle cells (HCASMCs).

\section{Materials and methods}

\subsection{Materials}

All chemicals and reagents were purchased either from SigmaAldrich or Fisher Scientific, USA and used without purification unless otherwise noted. 2-Propyl acrylic acid (PAA), ${ }^{33} N$-hydroxyl succinimide functional 4-cyano-4-(ethylsulfanylthiocarbonyl) sulfanylpentanoic acid (NHS-ECT) ${ }^{21}$ and 4-cyano-4-(ethylsulfanylthiocarbonyl) sulfanylpentanoic acid (ECT) ${ }^{34}$ were synthesized following previously reported protocols. The monomers, $N, N$-dimethylaminoethyl methacrylate (DMAEMA), and $N$-butyl methacrylate (BMA), were filtered twice through alumina columns just before polymerization. Maleimide end-functionalized methoxypolyethylene glycol ( $\mathrm{mPEG}_{113}$-MAL) was purchased from JenKem Technology USA (Allen, TX, USA). Rink amide-MBHA resin and Fmoc-protected L-amino acids were purchased from EMD Biosciences (Gibbstown, NJ, USA). Luciferase reporter plasmid (pPK-CMV-R3) with 5500 base pairs was purchased from Promokine (Heidelberg, Germany). Penicillin-streptomycin, fetal bovine serum (FBS) and lipofectamine2000 (LF2K) transfection reagent were purchased from Life Technologies (Carlsbad, CA, USA). 3-Morpholinosydnonimine (SIN-1) was purchased from Life Technologies as a package of $1 \mathrm{mg}$ plastic vials. Label IT $^{\circledR}$ Fluorescein Plasmid Delivery Control was purchased from Mirus Bio (Madison, WI, USA). A bifunctional HS- $\mathrm{CP}_{5} \mathrm{~K}^{-} \mathrm{NH}_{2}$ peptide (CPPPPPK) was synthesized by the standard FMOC-based solid phase method on a Rink amide-MBHA resin using PS3 synthesizer (Protein Technologies, Tucson, AZ, USA) and characterized by liquid chromatography-mass spectrometry (LC-MS). ${ }^{25}$

\subsection{Synthesis of ROS cleavable $\mathrm{MPEG}_{113}-b-\mathrm{CP}_{5} \mathrm{~K}-\boldsymbol{b}$ - PDMAEMA $_{42}$ - $b$-P(DMAEMA 22 -co-BMA 40 -co-PAA 24 ) (PPDDBP)}

This polymer was synthesized using the following steps.

2.2.1. Synthesis of $\mathbf{m P E G}_{113}-\boldsymbol{b}-\mathbf{C P}_{5} \mathbf{K}-\mathbf{N H}_{2}$. A degassed solution of triethyl amine $\left(\mathrm{Et}_{3} \mathrm{~N}\right)(0.176 \mathrm{mM}, 0.024 \mathrm{~mL})$ in a methanol/ acetonitrile mixture $(1: 1$ ratio, $25 \mathrm{~mL}$ ) was added to a previously dried flask containing $\mathrm{mPEG}_{113}$-MAL $(0.08 \mathrm{mM}, 0.4 \mathrm{~g})$ and $\mathrm{CP}_{5} \mathrm{~K}$ peptide $(0.12 \mathrm{mM}, 93 \mathrm{mg})$, followed by stirring at room temperature (RT) for $24 \mathrm{~h}$. The reaction mixture was purified by dialysis against methanol using $2 \mathrm{k}$ MW cutoff tubing for $24 \mathrm{~h}$ to yield purified $\mathrm{mPEG}_{113}-b-\mathrm{CP}_{5} \mathrm{~K}^{-\mathrm{NH}_{2}}$.

2.2.2. Synthesis of $\mathrm{mPEG}_{113}-\boldsymbol{b}-\mathrm{CP}_{5} \mathrm{~K}-\mathrm{ECT}$. A previously degassed solution of triethyl amine $(0.08 \mathrm{mM}, 0.012 \mathrm{~mL})$ in anhydrous methanol $(10 \mathrm{~mL})$ and DMF $(10 \mathrm{~mL})$ was added to a dried, degassed flask containing $\mathrm{mPEG}_{113}-b-\mathrm{CP}_{5} \mathrm{~K}-\mathrm{NH}_{2}(0.04 \mathrm{mM}$, $0.231 \mathrm{~g})$ and NHS-ECT $(0.1 \mathrm{mM}, 0.036 \mathrm{~g})$ with stirring for $48 \mathrm{~h}$. The reaction mixture was purified by precipitating in cold diethyl ether. Dried polymers were used for UV based absorption measurement at $310 \mathrm{~nm}$ to determine the percentage ECT conjugation to $\mathrm{mPEG}_{113}-b-\mathrm{CP}_{5} \mathrm{~K}-\mathrm{NH}_{2}$. 
2.2.3. Synthesis of mPEG $_{113}-b-C_{5} K-b$-pDMAEMA ${ }_{42}$-ECT. mPEG $_{113}-b$-CP 5 K-ECT (0.072 g, $\left.0.012 \mathrm{mM}\right)$, DMAEMA $(0.27 \mathrm{~mL}$, $1.17 \mathrm{mM}$ ) and AIBN (0.21 $\mathrm{mg}, 0.0013 \mathrm{mM})$ were dissolved in dioxane $(5 \mathrm{~mL})$ in a $15 \mathrm{~mL}$ glass ampoule and degassed by purging with nitrogen gas for $30 \mathrm{~min}$. The degassed solution was submerged in a preheated oil bath at $70{ }^{\circ} \mathrm{C}$ for $8 \mathrm{~h}$. The crude polymerization mixture was purified by dialysis $(2 \mathrm{k}$ MW cutoff tubing) against methanol and vacuum dried.

2.2.4. Synthesis of PPEG $_{113}-b-C_{5} \mathrm{~K}-b$-PDMAEMA $\mathrm{A}_{42}-\boldsymbol{b}$ P(DMAEMA 22 -co-BMA (D0 -co-PAA 24 ) (PPDDBP). mPEG $_{113}-b-\mathrm{CP}_{5} \mathrm{~K}-$ $b$-PDMAEMA 42 -ECT $(0.062 \mathrm{~g}, 0.005 \mathrm{mM})$, DMAEMA $(0.399 \mathrm{mM}$, $0.067 \mathrm{~mL}$ ), BMA (0.74 mM, $0.117 \mathrm{~mL})$, PAA (0.285 mM, $0.032 \mathrm{~g}$ ), AIBN (0.08 mg, $0.0005 \mathrm{mM})$, dioxane (4.5 mL) and DMF $(1.5 \mathrm{~mL})$ were placed in a dry glass ampoule, and the solution was degassed by nitrogen bubbling for $30 \mathrm{~min}$. Polymerization was conducted at $70{ }^{\circ} \mathrm{C}$ for $24 \mathrm{~h}$. The crude polymer mixture was purified by dialysis ( $2 \mathrm{k}$ MW cutoff tubing) first against methanol and then against water, and finally lyophilized.

2.3. Synthesis of control polymer without ROS cleavable $C_{5} \mathrm{~K}$ peptide, mPEG $_{113}-b$-PDMAEMA ${ }_{50}-b$-P(DMAEMA ${ }_{16}-c o-\mathrm{BMA}_{42}-c o$ $\mathbf{P A A}_{17}$ ) (PDDBP)

This block copolymer was synthesized through following steps.

2.3.1. Synthesis of mPEG $_{\mathbf{1 1 3}}$-ECT. $\mathrm{MPEG}$ based RAFT macro chain trasfer agent (CTA) was synthesized following a previously published protocol. ${ }^{34}$ In a $100 \mathrm{~mL}$ flask, mPEG $_{113}-\mathrm{OH}(2 \mathrm{mmol}$, $10 \mathrm{~g}, M_{\mathrm{n}}=5 \mathrm{kDa}$ ), ECT (4 mmol, $1.045 \mathrm{~g}$ ) and DMAP (10 mg) were dissolved in anhydrous dichloromethane $(100 \mathrm{~mL})$ by stirring at RT. Dicyclohexylcarbodimide (DCC, $4 \mathrm{mmol}, 0.82 \mathrm{~g}$ ) was then added to the solution and stirred for $48 \mathrm{~h}$ under nitrogen atmosphere. The white precipitate of dicyclohexyl urea was filtered. The filtrate was concentrated under vacuum and further precipitated three times into cold diethyl ether. The precipitated polymer was dried under vacuum. ${ }^{1} \mathrm{H}$ NMR spectra revealed $81 \%$ conjugation of ECT to $\mathrm{mPEG}$. The molecular weight $\left(M_{\mathrm{n}}\right)$ and polydispersity (PDI) of polymer were 5300 and 1.05, respecively, as determined by gel permeation chromatography (GPC).

2.3.2. Synthesis of $\mathbf{m P E G}_{113}$ - $\boldsymbol{b}$-PDMAEMA $\mathbf{P}_{\mathbf{5 0}}$-ECT. In a glass test tube, $\mathrm{mPEG}_{113}$-ECT (0.064 g, $0.012 \mathrm{mmol}, M_{\mathrm{n}}$ 5300), DMAEMA (0.27 mL, $1.17 \mathrm{mmol}$ ), and AIBN (0.21 mg, $0.0012 \mathrm{mmol}$ ) were dissolved in dioxane $(5 \mathrm{~mL})$ and degassed by purging with nitrogen for 30 minutes. The degassed solution was submerged in a preheated oil bath at $70{ }^{\circ} \mathrm{C}$ for $8 \mathrm{~h}$. The final polymerization mixture was quenched by exposure to air at RT. The polymer was purified by precipitation into tenfold excess cold diethyl ether, and then dried under vacuum. The polymer $M_{\mathrm{n}}$ and PDI were 14800 and 1.55, respectively, as determined by GPC.

2.3.3. Synthesis of 'PEG $_{113}-b$-PDMAEMA ${ }_{50}-b$-P(DMAEMA ${ }_{16}^{-}$ co-BMA $\mathbf{B 2}_{\mathbf{2}}$-co-PAA ${ }_{17}$ ) (PDDBP). A chain extension of $\mathrm{mPEG}_{113}-b$ pDMAEMA $_{50}-$ ECT $^{-}$was carried out to prepare PPEG $_{113}-b$-PDMAEMA ${ }_{50}-$ $b$-P(DMAEMA $\left.{ }_{16}-\mathrm{Co}-\mathrm{BMA}_{42}-\mathrm{co}-\mathrm{PAA}_{17}\right)$ by RAFT polymerization of DMAEMA, BMA and PAA. Briefly, mPEG $_{113}-b$-PDMAEMA PD -ECT $\left(0.075 \mathrm{~g}, 0.005 \mathrm{mmol}, M_{\mathrm{n}} 15000\right)$, DMAEMA $(0.067 \mathrm{~mL}$, $0.399 \mathrm{mmol})$, BMA (0.74 mmol, $0.117 \mathrm{~mL})$, PAA (0.285 mM, $0.032 \mathrm{~g})$, AIBN (0.08 $\mathrm{mg}, 0.0005 \mathrm{mmol})$, dioxane $(4.5 \mathrm{~mL})$ and DMF $(1.5 \mathrm{~mL})$ were placed in a dry ampoule, and the solution was degassed by bubbling nitrogen for 30 minutes. The polymerization was performed at $70{ }^{\circ} \mathrm{C}$ for $24 \mathrm{~h}$. The crude polymerization mixture was purified by precipitation twice in cold diethylether. The polymer $M_{\mathrm{n}}$ and PDI were 25300 and 1.22, respectively, as determined by GPC.

\subsection{Polymer characterization}

${ }^{1} \mathrm{H}$ NMR spectra of organic compounds and polymers were collected in $\mathrm{CDCl}_{3}$ with a Brüker $400 \mathrm{MHz}$ spectrometer. GPC (Agilent Technologies, Santa Clara, CA, USA) was used to determine the $M_{\mathrm{n}}$ and PDI of polymers in dimethylformamide $(\mathrm{DMF})+0.1 \mathrm{M} \mathrm{LiBr}$ mobile phase at $60{ }^{\circ} \mathrm{C}$ through three serial Tosoh Biosciences TSKGel Alpha columns (Tokyo, Japan). A Wyatt miniDAWN TREOS light scattering (LS) detector (Wyatt Technology Corp., Santa Barbara, CA, USA) and Agilent refractive index (RI) detector were used to calculate absolute $M_{\mathrm{n}}$ based on $\mathrm{d} n / \mathrm{d} c$ values experimentally determined through offline injection into the RI detector.

\subsection{Preparation and characterization of polymer micelles}

To prepare polymer micelles, either lyophilized PPDDBP or non-cleavable PDDBP (10 mg) was dissolved in $200 \mu \mathrm{L}$ of methanol, followed by addition of $\mathrm{pH} 4.0$ buffer $(200 \mu \mathrm{L})$. Micelle formation was induced by drop wise addition of $\mathrm{pH}$ 8.0 buffer $(10 \mathrm{~mL})$ to the magnetically stirred polymer suspension using a syringe pump. Polymer micelles were filtered through a 0.2 micron syringe filter just before size and zeta potential measurements by dynamic light scattering (DLS, Malvern Zetasizer Nano ZS, Malvern, UK). To measure critical micelle concentration (CMC) of PPDDBP micelles, a range of polymer concentration from 0.01 to $1 \mathrm{mg} \mathrm{mL}^{-1}$ in DPBS was prepared, and stability of micelles was measured by DLS. ${ }^{35}$ ROS mediated cleavage of peptide and subsequent changes in zeta potential of micelles in PBS were determined in the presence of $4 \mathrm{mM}$ SIN-1 (a generator of peroxynitrite that decomposes into nitric oxide and superoxide in an aqueous solution).

\subsection{Assessment of ROS-triggered detachment of PEG from PPDDBP by GPC}

To confirm ROS-mediated dePEGylation of PPDDBP polymer through cleavage of $\mathrm{CP}_{5} \mathrm{~K}$ peptide, lyophilized PPDDBP (10 $\mathrm{mg} \mathrm{mL}^{-1}$ ) was incubated with $1 \mathrm{mM} \mathrm{SIN-1}$ in DPBS at RT for $16 \mathrm{~h}$. The polymer solution was then lyophilized and dissolved into DMF to run in GPC. The cleavage of $\mathrm{CP}_{5} \mathrm{~K}$ peptide was confirmed by comparing GPC chromatograms of PPDDBP before and after SIN-1 treatment.

\subsection{Preparation and characterization of polyplexes}

Lyophilized PPDDBP or noncleavable PDDBP polymer at various $\mathrm{N} / \mathrm{P}$ ratios were mixed with pDNA $\left(1.5 \mu \mathrm{g} \mathrm{mL}{ }^{-1}\right)$ in a $100 \mathrm{mM}$ citric acid/sodium citrate buffer solution ( $\mathrm{pH} 4.0)$. After $30 \mathrm{~min}$ incubation at RT, polyplex formation was induced by addition of $\mathrm{pH} 8.0$ buffer to raise the $\mathrm{pH}$ up to 7.4. The size and zeta potential $(\zeta)$ of the polyplexes (N/P 10) were determined using DLS (Malvern Zetasizer Nano ZS). To see ROS mediated dePEGylation of polyplexes, changes in zeta potential of polyplexes 
$(\mathrm{N} / \mathrm{P} 10)$ were measured in the presence of SIN-1 (4 mM) over $24 \mathrm{~h}$. Transmission electron microscopy (TEM) samples were prepared on carbon film-backed copper grid (Electron Microscopy Sciences, Hatfield, PA, USA) by addition of a polyplex solution ( $5 \mu \mathrm{L}, \mathrm{N} / \mathrm{P} 10)$ for 60 seconds, followed by dry blotting. Next, the samples were counter stained with filtered $3 \%$ uranyl acetate $(5 \mu \mathrm{L})$ as a negative stain for 20 seconds and again blotted dry. The samples were then dried under vacuum overnight and imaged using a FEI Tecnai Osiris TEM at $200 \mathrm{kV}$.

\subsection{Assessment of pDNA loading by agarose gel electrophoresis}

The ability of PPDDBP to condense pDNA was assessed by agarose gel electrophoresis. The polyplexes at various N/P ratios $\left(1,2,5,10,20\right.$, and 30) were loaded with $10 \mu \mathrm{g} \mathrm{mL} \mathrm{m}^{-1} \mathrm{pDNA}$, and the samples were run into $0.5 \%$ agarose gel containing $0.05 \mu \mathrm{g} \mathrm{mL}$ ethidium bromide (EtBr). Naked pDNA was used as a positive control. The gel electrophoresis was performed in TAE $(1 \times)$ buffer at $100 \mathrm{~V}$ for $30 \mathrm{~min}$. The bands were visualized and imaged with a UV trans-illuminator.

\subsection{Stability of polyplexes in the presence of serum and SDS decomplexation}

PPDDBP polyplexes (N/P 10) were incubated in a high concentration $(50 \% \mathrm{w} / \mathrm{v})$ of fetal bovine serum (FBS) at $37{ }^{\circ} \mathrm{C}$ for 0.25 , $0.5,1,2,3$, and $6 \mathrm{~h}$. As a harsh control condition to prove the DNase protection capability of the polyplexes, a solution of sodium dodecyl sulfate (SDS, $1 \% \mathrm{w} / \mathrm{v}$ ) was added to cause release of pDNA. The samples were analyzed by gel electrophoresis as described above.

\subsection{Hemolysis assay}

The blood cytocompatibility of polymer alone and pDNA/ PPDDBP polyplexes was measured by a $\mathrm{pH}$ dependent hemolysis assay. ${ }^{23}$ Briefly, red blood cells (RBCs) were isolated from anonymous, consenting human donors according to well established protocols. ${ }^{23} 10 \mu \mathrm{L}$ solutions of PPDDBP or polymer/pDNA polyplexes (at polymer concentrations of $20-800 \mu \mathrm{g} \mathrm{mL}{ }^{-1}$ ) were incubated with RBCs $(190 \mu \mathrm{L})$ in DPBS in four different $\mathrm{pH}$ conditions (7.4. 6.8, 6.2 and 5.8) that mimic extracellular and endosomal trafficking. The RBCs treated with DPBS and 1\% (v/v) Triton X-100 were used as negative and positive controls, respectively. After $1 \mathrm{~h}$ of incubation at $37{ }^{\circ} \mathrm{C}$, RBCs were centrifuged at $500 \mathrm{~g}$ for $5 \mathrm{~min}$, and supernatant was measured using the M100 Pro plate reader by recording the absorbance at $541 \mathrm{~nm}$ to determine the percent hemolysis of samples compared to the positive control treated with Triton-X-100.

\subsection{Cell viability}

Cell viability of HCASMCs was measured by a resazurin assay. ${ }^{36}$ HCASMCs were seeded in 24-well plates at a density of $4 \times 10^{4}$ cells per well with $500 \mu \mathrm{L}$ of SMC medium (Cell Applications Inc, San Diego, CA) and allowed to adhere for $24 \mathrm{~h}$. Afterwards, the culture media was replaced with a fresh solution of media containing polyplexes $\left(1.5 \mu \mathrm{g} \mathrm{mL}^{-1}\right)$ with various $\mathrm{N} / \mathrm{P}$ ratio
$(1,2,4,8,10$, and 20) or lipofectamine 2000 (LF2K) (N/P10). After $24 \mathrm{~h}$ of culture, cells were incubated with fresh media containing resazurin sodium salt $(5 \mu \mathrm{M})$ (Sigma-Aldrich) for $4 \mathrm{~h}$ at $37{ }^{\circ} \mathrm{C}$ in the dark. The incubated culture media was then transferred to a new 96 -well plate $(100 \mu \mathrm{L}$ per well), and the fluorescence intensity was measured by a plate reader at 530$560 \mathrm{~nm}$ excitation wavelength and $590 \mathrm{~nm}$ emission wavelength. The percent cell viability for each group was calculated based on a standard curve obtained from cell culture on tissue culture polystyrene (TCPS) $(n=3)$.

\subsection{Measurement of intracellular ROS levels in HCASMCs by flow cytometry}

Intracellular ROS levels were measured by CM- $\mathrm{H}_{2}$ DCFDA staining with flow cytometric analysis. ${ }^{37}$ HCASMCs $\left(4.0 \times 10^{4}\right.$ cells per well in a 24-well plate) were cultured in Dulbecco's modified Eagle's medium (DMEM, Gibco Cell Culture, Carlsbad, CA, USA) containing $2 \%$ FBS and 1\% streptomycin/penicillin for $24 \mathrm{~h}(n=3)$. A freshly prepared, sterile CM- $\mathrm{H}_{2}$ DCFDA solution $(10 \mathrm{mM})$ in dimethylsulfoxide (DMSO) $(8.65 \mu \mathrm{L})$ was added to the media $(8.65 \mathrm{~mL})$ to obtain $10 \mu \mathrm{M}$ concentration, and this media was incubated with cells in the dark for $20 \mathrm{~min}$ at $37{ }^{\circ} \mathrm{C}$. The cells were washed twice with DPBS $(500 \mu \mathrm{L})$ to remove any free residual dye and detached using $0.05 \%$ trypsin $(200 \mu \mathrm{L})$ for $5 \mathrm{~min}$. Then fresh media $(500 \mu \mathrm{L})$ was added to the cells, and the fluorescence intensity of $\mathrm{CM}-\mathrm{H}_{2}$-DCFDA was analyzed by running 10000 cells per sample in flow cytometry (FACSCalibur flow cytometer, BD Biosciences, Franklin Lakes, NJ, USA) at excitation at $488 \mathrm{~nm}$ with a 530/30 filter.

\subsection{Cellular uptake of polyplexes by flow cytometry}

To evaluate cellular uptake of polyplexes, HCASMCs $(1.0 \times$ $10^{5}$ cells per well in a 12 -well plate) were cultured in SMC medium (Cell Applications Inc.) for $24 \mathrm{~h}$. Cells were then treated with lipopolysaccharide (LPS, $1 \mu \mathrm{g} \mathrm{mL}{ }^{-1}$ ) and interferon gamma (IFN)- $\gamma$ (100 units per $\mathrm{mL}$ ) in fresh culture media for $6 \mathrm{~h}$ to induce ROS production. Polyplexes were prepared from either ROS cleavable PPDDBP or non-cleavable PDDBP (both with N/P 10) by loading fluorescein labeled pDNA (Mirus Bio) at a final concentration of $1.5 \mu \mathrm{g} \mathrm{mL}{ }^{-1}$. Cells with or without LPS/ IFN- $\gamma$ were then incubated with these polyplexes $(n=3)$ for $6 \mathrm{~h}$, washed twice with DPBS, and detached with $0.05 \%$ trypsin. Cellular uptake of particles was measured by FACSCalibur flow cytometry (BD Biosciences) and analyzed with the BD Cell Quest ProTM software.

\subsection{Imaging intracellular distribution of polyplexes by confocal laser scanning microscopy}

To track intracellular localization of polyplexes, HCASMCs $\left(1 \times 10^{4}\right.$ cells per well $)$ were cultured in a Falcon 8 -well culture slide (BD Biosciences) for $24 \mathrm{~h}$. HCASMCs were then treated with LPS $\left(1 \mu \mathrm{g} \mathrm{mL}^{-1}\right)$ and IFN- $\gamma(100$ units per $\mathrm{mL})$ in fresh culture media for $6 \mathrm{~h}$ to induce ROS production. Polyplexes (N/P 10) were prepared by loading fluorescein labelled pDNA (Mirus Bio) at the final concentration of $1.5 \mu \mathrm{g} \mathrm{mL}{ }^{-1}$ to ROS cleavable PPDDBP, and control PDDBP. HCASMCs with or 
without LPS/IFN- $\gamma$ were incubated with the polyplexes with $(n=$ 3) for $6 \mathrm{~h}$, and then treated with Lysotracker (Life Technologies, NY, USA) for $1 \mathrm{~h}$ and imaged by confocal laser scanning microscopy (Nikon, TE2000). The confocal images were analyzed using Image (NIH, Maryland, USA). For measuring in vitro plasmid uptake by HCASMCs, the average intensity by green fluorescent plasmids within the total individual cell area was measured for $N=10-15$ cells per each condition using ImageJ (NIH, US), and averaged for each condition.

\subsection{In vitro transfection efficiency}

In vitro transfection efficiency of polyplexes in HCASMCs was assessed by a luciferase gene reporter assay. HCASMCs were cultured in 96-well plates (12000 cells per well for $\sim 70-80 \%$ confluent) in SMC medium for $24 \mathrm{~h}$. Cells were then treated with LPS $\left(1 \mu \mathrm{g} \mathrm{mL}{ }^{-1}\right)$ and IFN- $\gamma(100$ units per $\mathrm{mL})$ for $6 \mathrm{~h}$ to induce ROS production, followed by treatment with PPDDBP and LF2K polyplexes at N/P 10 ratio for $24 \mathrm{~h}$ at $37{ }^{\circ} \mathrm{C}$. Luciferin $\left(150 \mu \mathrm{g} \mathrm{mL}^{-1}\right)$ was added to the samples, and bioluminescence from cells was measured using a Xenogen IVIS Imaging system 200 series (Perkin Elmer, Waltham, MA, USA). Cells were then washed twice with DPBS and lysed with $200 \mu \mathrm{L}$ of lysis buffer (Promega, Madison, WI, USA). The protein content was using a microBCA protein assay reagent kit (Pierce) and reading absorbance at $562 \mathrm{~nm}$ using the M1000 Pro platen reader. The luciferase expression was reported in relative light units (RLU) normalized to $\mathrm{mg}$ protein (RLU per $\mathrm{mg}$ ).

\subsection{Statistical analysis}

The experimental results are reported as means \pm standard error mean (SEM). Data from each experiment were initially analyzed using single factor analysis of variance, and comparisons between individual samples were then performed using an unpaired Student's $t$-test. For all statistics $p<0.05$ was considered significantly different.

\section{Results and discussion}

\subsection{Polymer synthesis and characterization}

The ROS-cleavable oligo-proline peptide $\left(\mathrm{CP}_{5} \mathrm{~K}\right)$ conjugated PEGylated copolymer, PPDDBP was synthesized as described in Scheme 1. First, the oligo-proline peptide $\left(\mathrm{SH}-\mathrm{CP}_{5} \mathrm{~K}-\mathrm{NH}_{2}\right)$ containing five proline units $\left(\mathrm{P}_{5}\right)$ between a thiol $(-\mathrm{SH})$ group of cysteine at one end and a primary amine $\left(-\mathrm{NH}_{2}\right)$ of lysine at the other terminus was synthesized by fluorenylmethyloxycarbonylchloride (FMOC)-based peptide synthesis. ${ }^{25}$ The formation of the $\mathrm{CP}_{5} \mathrm{~K}$ peptide was confirmed by the presence of single characteristic mass peak at $m / z 776$ in LC-MS spectrum (Fig. S1, ESI $\dagger$ ). The peptide, $\mathrm{CP}_{5} \mathrm{~K}$ was conjugated with $5 \mathrm{kDa}$ maleimide-functionalized methoxypolyethylene glycol $\left(\mathrm{mPEG}_{113}-\mathrm{MAL}\right)$ through the thiol group of cysteine end by maleimide-thiol coupling chemistry. The conjugation of $\mathrm{mPEG}_{113}-b-\mathrm{CP}_{5} \mathrm{~K}-\mathrm{NH}_{2}$ was confirmed by a left-shift in the GPC chromatogram (Fig. 1). Second, in order to build the other polymer blocks on this mPEG-peptide conjugate, the amine group of $\mathrm{mPEG}_{113}-b-\mathrm{CP}_{5} \mathrm{~K}-\mathrm{NH}_{2}$ was coupled with NHSECT, yielding mPEG $_{113}-b-\mathrm{CP}_{5} \mathrm{~K}-\mathrm{ECT}$, a macro initiator for RAFT polymerization.

The formation of RAFT macro chain transfer agent (CTA) was confirmed by a shift in GPC chromatogram and by UV absorption of the trithiocarbonate group of CTA at $310 \mathrm{~nm}$. Based on the CTA extinction coefficient, the conjugation efficiency of 4-cyano-4-(ethylsulfanylthiocarbonyl) sulfanylpentanoic acid (ECT) to $\mathrm{mPEG}_{113}-b$ $\mathrm{CP}_{5} \mathrm{~K}_{-} \mathrm{NH}_{2}$ was $98 \%$. This macro-CTA was then used for RAFT polymerization of DMAEMA using azobisisobutyronitrile (AIBN)

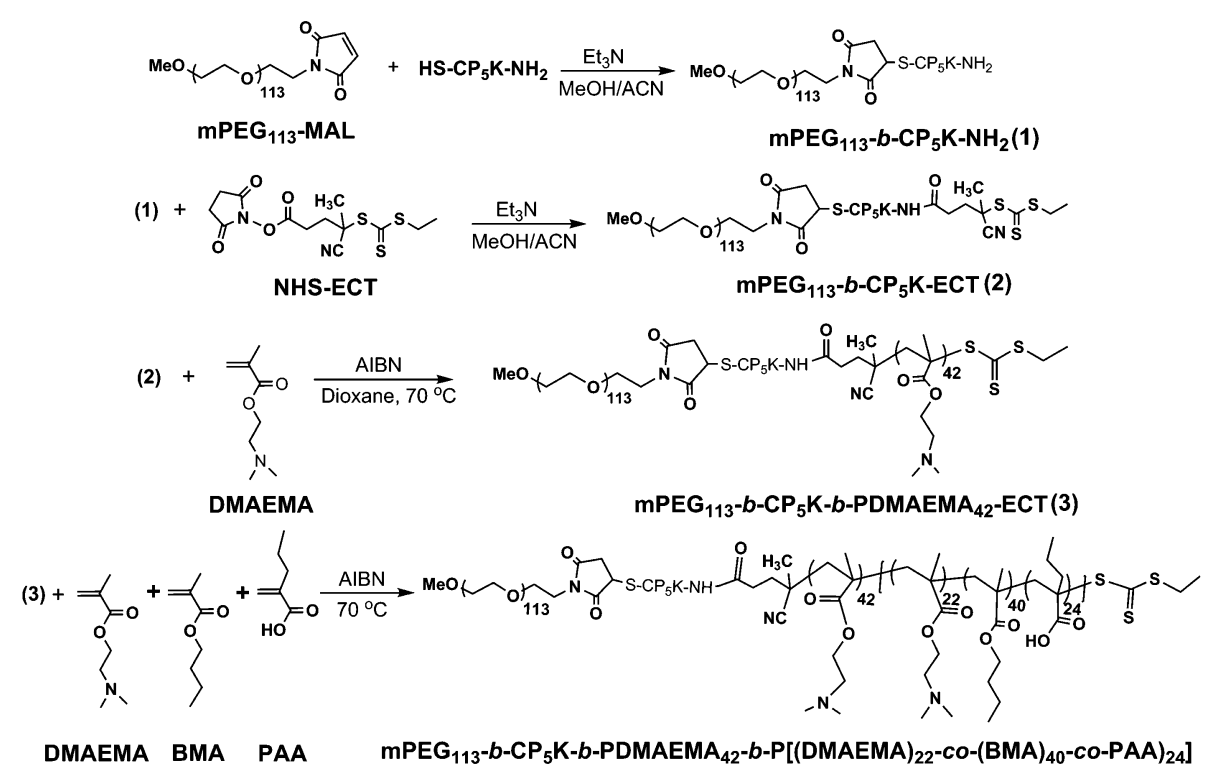

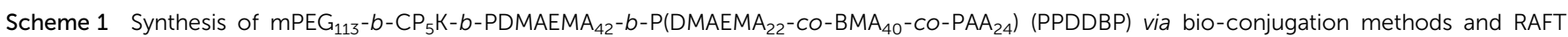
polymerization. 


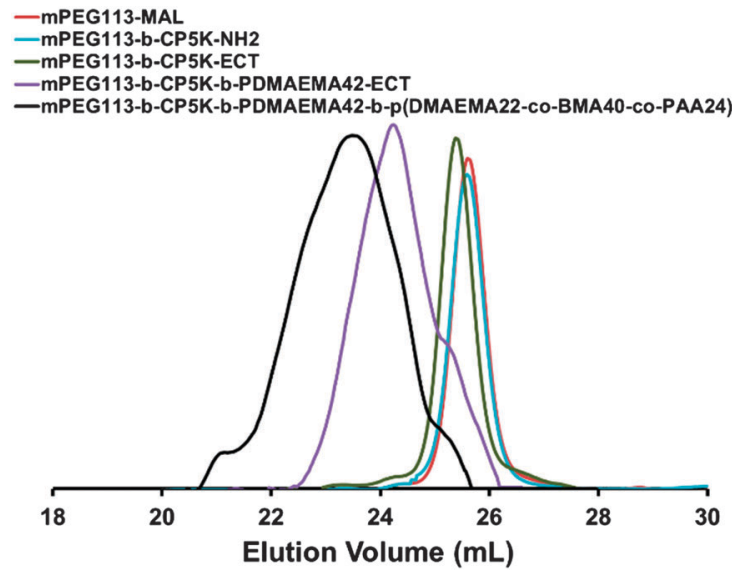

Fig. 1 GPC refractive index detector traces of $\mathrm{mPEG}_{113}-\mathrm{MAL}, \mathrm{mPEG}_{113}-b-$ $\mathrm{CP}_{5} \mathrm{~K}-\mathrm{NH}_{2}, \quad \mathrm{mPEG}_{113}-b-\mathrm{CP}_{5} \mathrm{~K}-\mathrm{ECT}, \quad \mathrm{PPEG}_{113}-b-\mathrm{CP}_{5} \mathrm{~K}-b-\mathrm{PDMAEMA}_{42}-\mathrm{ECT}$, and $\mathrm{mPEG}_{113}-b-\mathrm{CP}_{5} \mathrm{~K}-b-\mathrm{PDMAEMA}{ }_{42}-b-\mathrm{P}\left(\mathrm{DMAEMA}_{22}-\mathrm{CO}-\mathrm{BMA}_{40}-\mathrm{CO}-\mathrm{PAA}_{24}\right)$ (PPDDBP).

in dioxane, yielding $\mathrm{mPEG}_{113}-b-\mathrm{CP}_{5} \mathrm{~K}-b$-PDMAEMA ${ }_{42}$-ECT. The number of repeating DMAEMA units in the PDMAEMA block of copolymer was calculated from ${ }^{1} \mathrm{H}$ NMR spectra by comparing the integration of $\mathrm{CH}_{2}$ protons of DMAEMA at $4.15 \mathrm{ppm}$ to the $-\mathrm{OCH}_{2}$ peak of mPEG block at $3.65 \mathrm{ppm}$. Finally, a chain extension of $\mathrm{mPEG}_{113}-b-\mathrm{CP}_{5} \mathrm{~K}-b$-pDMAEMA $\mathrm{p}_{42}$-ECT was performed to prepare mPEG $_{113}-b-\mathrm{CP}_{5} \mathrm{~K}-b$-PDMAEMA $42-b-\mathrm{P}\left(\mathrm{DMAEMA}_{22}-c o-\mathrm{BMA}_{40}-c o-\mathrm{PAA}_{24}\right)$ (PPDDBP) by RAFT polymerization of DMAEMA, BMA and PAA in dioxane/DMF mixture (3:1) using AIBN at $70{ }^{\circ} \mathrm{C}$ for $24 \mathrm{~h}$ (Fig. 1).

The numbers of repeating DMAEMA, BMA, and PAA units in the random terpolymer block of the final copolymer were calculated by relative integration of the $\mathrm{mPEG}$ block peak at 3.65 ppm with $\mathrm{CH}_{2}$ protons from DMAEMA, BMA and PAA at 4.15, 4.0 and $1.2 \mathrm{ppm}$, respectively (Table 1 and Fig. S2, ESI $\dagger$ ). ${ }^{21}$

To prepare non-cleavable control polymer $\mathrm{mPEG}_{113}-b$ PDMAEMA $_{50}-b$-P(DMAEMA $\left.16-c o-\mathrm{BMA}_{42}-c o-\mathrm{PAA}_{17}\right)$ (PDDBP) without the $\mathrm{CP}_{5} \mathrm{~K}$ peptide, the first terminal hydroxyl group of $5 \mathrm{k}$ mPEG was conjugated with the carboxylic group of ECT by a DCC/DMAP method, producing mPEG $_{113}$-ECT as a RAFT macro CTA. This CTA was used to further build the second block as PDMAEMA. Subsequently, mPEG $_{113}$ - $b$-PDMAEMA P0 $_{5}$-ECT was utilized for the third block as P(DMAEMA-co-BMA-co-PAA) random copolymer under similar polymerization conditions as described for PPDDBP (Scheme S1, Table S1, Fig. S3 and S4, ESI $\dagger$ ).

Table 1 Molecular weight of polymers prepared by bio-conjugation methods and controlled RAFT polymerization

\begin{tabular}{|c|c|c|c|c|}
\hline S. No. & Polymer & $M_{\mathrm{n}, \mathrm{NMR}}{ }^{a}$ & $M_{\mathrm{n}, \mathrm{GPC}}^{b}$ & $\mathrm{PDI}^{c}$ \\
\hline 1 & $\mathrm{mPEG}_{113}-\mathrm{MAL}$ & 5000 & 5000 & 1.05 \\
\hline 2 & $\mathrm{mPEG}_{113}-b-\mathrm{CP}_{5} \mathrm{~K}-\mathrm{NH}_{2}$ & 5776 & 5700 & 1.05 \\
\hline 3 & $\mathrm{mPEG}_{113}-b-\mathrm{CP}_{5} \mathrm{~K}-\mathrm{ECT}$ & 6135 & 6000 & 1.0 \\
\hline 4 & mPEG $_{113}-b-\mathrm{CP}_{5} \mathrm{~K}-b$-PDMAEMA ${ }_{42}$-ECT & 12737 & 13700 & 1.15 \\
\hline 5 & $\begin{array}{l}\text { mPEG }_{113}-b-\mathrm{CP}_{5} \mathrm{~K}-b-\mathrm{PDMAEMA}_{42}-b- \\
\mathrm{P}\left(\mathrm{DMAEMA}_{22}-c o-\mathrm{BMA}_{40}-c o-\mathrm{PAA}_{24}\right) \\
\text { (PPDDBP) }\end{array}$ & 24610 & 31500 & 1.22 \\
\hline
\end{tabular}

${ }^{a}$ Molecular weight $\left(M_{\mathrm{n}, \mathrm{NMR}}\right)$ of polymers calculate by ${ }^{1} \mathrm{H}$ NMR. ${ }^{b} \mathrm{Num}$ ber average molecular weight of polymer by GPC in DMF solvent.

${ }^{c}$ Polydispersity index (PDI) of polymers.

\subsection{Preparation and characterization of polymer micelles}

In aqueous media, ROS-responsive PPDDBP and uncleavable PDDBP assembled into stable micelles through hydrophilic PEG and PDMAEMA as corona and hydrophobic P(DMAEMA-co-BMAco-PAA) as core forming block with an average diameters of 37 and $46 \mathrm{~nm}$, respectively (Fig. S5A, ESI $\dagger$ ).

Their $\zeta$-potential values were $1.54 \mathrm{mV}$ and $0.9 \mathrm{mV}$ (Fig. S5B, ESI $\dagger$ ), respectively, indicating mPEG-mediated shielding of positivelycharged PDMAEMA. The PPDDBP micelles were stable down to $0.1 \mathrm{mg} \mathrm{mL}{ }^{-1}$ concentration but were destabilized at $0.01 \mathrm{mg} \mathrm{mL}^{-1}$ concentration. This observation indicates that the CMC of these micelles is between $0.1-0.01 \mathrm{mg} \mathrm{mL}^{-1}$ (Fig. S6, ESI $\dagger$ ).

\subsection{Confirmation of ROS-triggered dePEGylation of PPDDBP}

To confirm ROS-mediated dePEGylation of the nanocarrier, PPDDBP copolymer micelles were incubated overnight with a $1 \mathrm{mM}$ dose of SIN-1, a producer of peroxynitrite, ${ }^{38,39}$ in DPBS at pH 7.4. Fig. 2 shows GPC chromatograms of $\mathrm{mPEG}_{113}-\mathrm{MAL}$ and PPDDBP polymer before and after SIN-1 treatment. In the presence of SIN-1, a clear decrease in the polymer molecular weight with an appearance of a mPEG shoulder peak indicates ROS-mediated dePEGylation of polymer micelles through cleavage of $\mathrm{CP}_{5} \mathrm{~K}$ peptide. DePEGylation also increased the $\zeta$-potential from $1.54 \mathrm{mV}$ to $8.45 \mathrm{mV}$ for PPDDBP micelles (Fig. S5B, ESI $\dagger$ ) over a 20 hour incubation with $4 \mathrm{mM}$ concentration of SIN-1. In contrast, the zeta potential of the control PDDBP micelles remained unchanged (Fig. S5B, ESI $\dagger$ ). The increase in the zeta potential of the PPDDBP micelles compared to control (PDDBP) after SIN-1 treatment suggests that the cleavage of mPEG block from PPDDBP results in an exposure of the positively-charged amine groups of the PDMAEMA block in aqueous solution. To investigate the effect of SIN-1 mediated dePEGylation on size and stability of micelles, PPDDBP polymer micelles $\left(1 \mathrm{mg} \mathrm{mL}{ }^{-1}\right.$ ) in DPBS (pH 7.4) were incubated with SIN-1 (4 mM) for $24 \mathrm{~h}$. DLS measurement indicated that the size of polymer micelles $(47 \mathrm{~nm})$ remained unchanged

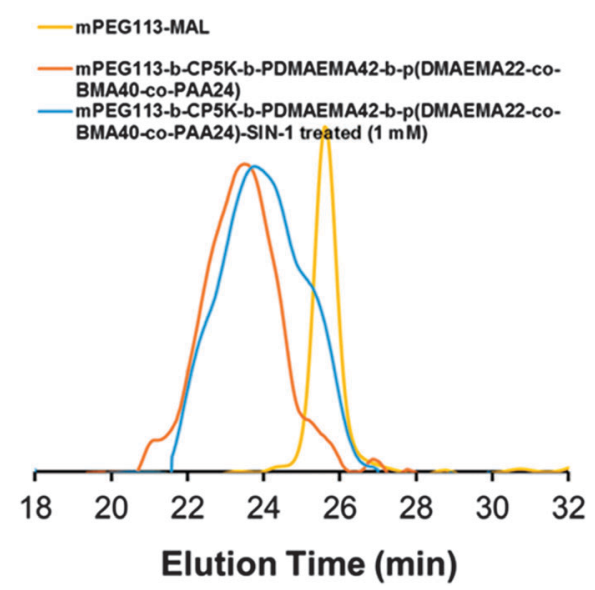

Fig. 2 GPC chromatograms of PPDDBP show ROS-mediated detachment of PEG block from PPDDBP polymer through cleavage of $\mathrm{CP}_{5} \mathrm{~K}$ peptide linkers after overnight treatment of SIN-1 (1 mM), evidenced by the appearance of shoulder peak of PPDDBP (blue) overlapping the PEG peak (yellow). 
after SIN-1 treatment, indicating the micelle stability was maintained by hydrophilic PDMAEMA corona and hydrophobic $\mathrm{P}(\mathrm{DMAEMA}-\mathrm{co}$-BMA-co-PAA) core. (Fig. $\mathrm{S} 7, \mathrm{ESI} \dagger$ ).

These results suggest that in ROS-rich microenvironments, the PPDDBP micelles would improve cellular uptake by triggering the interaction of positively-charged polymer micelles with the negatively-charged plasma.

\subsection{Preparation and characterization of PPDDBP/pDNA polyplexes}

The size and $\zeta$-potential of polyplexes were measured to determine their compatibility for intravenous delivery. ${ }^{40}$ To determine the stability of the polyplexes (N/P 10), we used DLS to characterize the size distribution, and observed a unimodal peak with an average diameter of $120 \mathrm{~nm}$ (Fig. 3A). The size distribution of polyplexes was further examined by TEM, which confirmed monodisperse particles with spherical morphology (Fig. 3B). The smaller size of the polyplexes in the TEM image compared to that measured by DLS can be explained by dehydration of the hydrophilic segments during TEM sample preparation. ${ }^{41}$

To further verify the ROS-mediated dePEGylation from polyplexes, PPDDBP/pDNA polyplexes (N/P 10) were incubated overnight with SIN-1 under similar condition as described for PPDDBP micelles in Fig. 4. The polyplex showed an increase in $\zeta$-potential from $1.55 \mathrm{mV}$ to $8.75 \mathrm{mV}$ after SIN-1 treatment. This observation indicates the polyplexes can undergo dePEGylation in response ROS overproduction, thereby improving cellular uptake through enabling positively charged PDMAEMA to interact with the negatively charged plasma membrane of target cells. $^{20,42}$

The condensation of PPDDBP with pDNA was examined by gel electrophoresis at various N/P ratios $(1,2,5,10,20$, and 30) and compared to free pDNA to determine the minimum amount of PPDDBP polymer required for effective polyplex formation with pDNA (Fig. S8, ESI $\dagger$ ). Regardless of the N/P ratios, all the polyplex groups showed no free pDNA, which indicates effective condensation of pDNA. ${ }^{43}$ To investigate the stability of polyplexes and protection of pDNA in serum, PPDDBP/pDNA polyplexes at N/P 10 ratios were incubated with $50 \%$ serum for $0.25,0.5,1,2,3$, and $6 \mathrm{~h}$. As shown in Fig. S9,
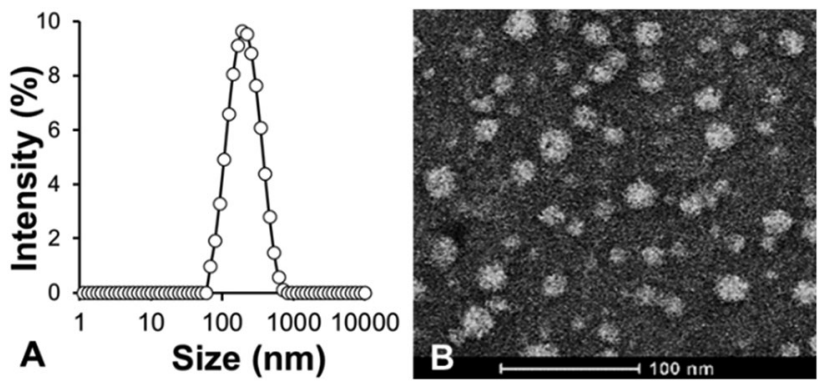

Fig. 3 Size and morphology of PPDDBP/pDNA polyplexes (A) DLS-based size measurement PPDDBP/pDNA polyplexes in DPBS (pH 7.4) at N/P 10 shows formation of stable polyplexes with an average diameter of $120 \mathrm{~nm}$ $(P D I=0.27)$. (B) TEM images of PPDDBP/pDNA polyplexes confirm the formation of stable polyplexes with spherical morphology.

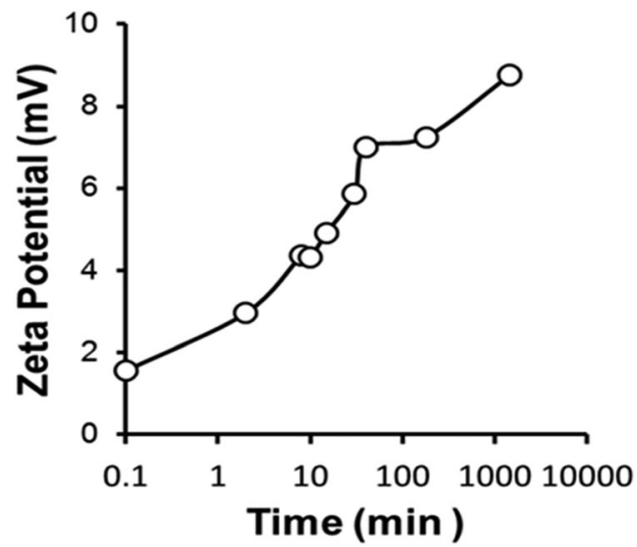

Fig. 4 ROS responsiveness of polyplexes by DLS based $\zeta$-potential. An increase in the $\zeta$-potential of polyplexes from 1.55 to $8.75 \mathrm{mV}$ after SIN-1 (4 mM) treatment for $24 \mathrm{~h}$ further confirms the detachment of PEG block via a ROS-mediated cleavage of $\mathrm{CP}_{5} \mathrm{~K}$ peptide linkers.

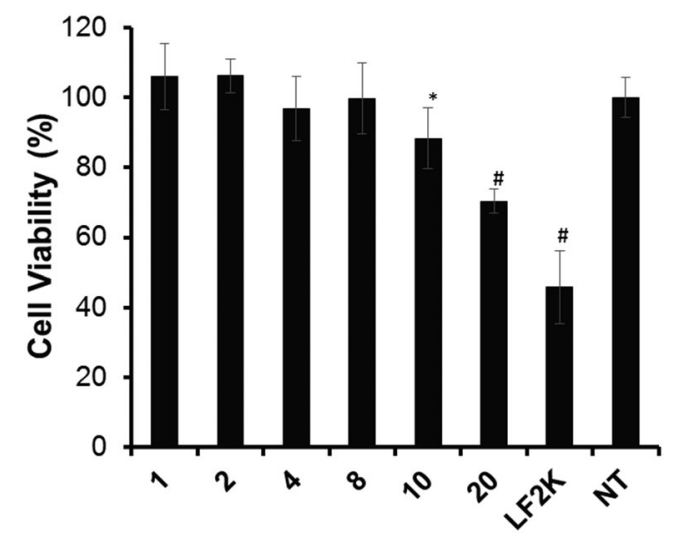

Fig. 5 In vitro cytotoxicity of PPDDBP/pDNA polyplexes at different N/P ratio $(1,2,4,8,10$, and 20$)$ was assessed by resazurin assay. Human coronary artery smooth muscle cells (HCASMCs) were incubated with PPDDBP/pDNA polyplexes or lipofectamine 2000 (LF2K) for $24 \mathrm{~h}$ before the endpoint assay $(n=3) ;{ }^{*} p<0.05$ vs. no treatment (NT); ${ }^{*} p<0.001$ vs. NT.

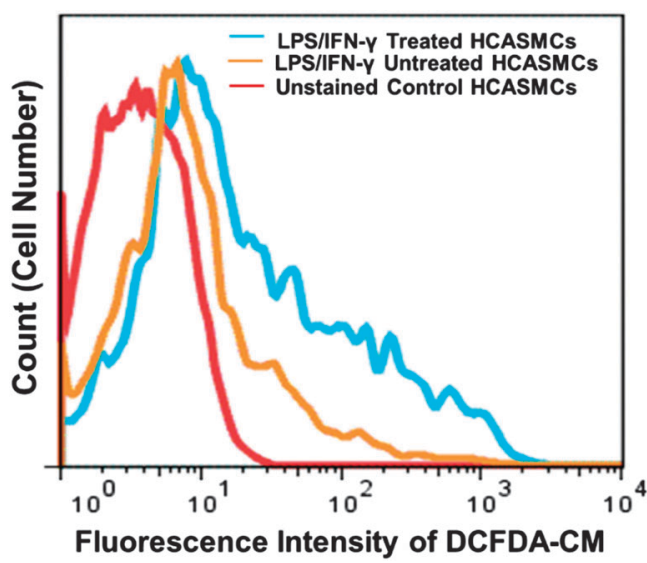

Fig. 6 Flow cytometric analysis of intracellular ROS levels in HCASMCs stained with $\mathrm{CM}-\mathrm{H}_{2}$ DCFDA $(10 \mu \mathrm{M})$ after treatment with or without LPS $\left(1 \mu \mathrm{g} \mathrm{mL}{ }^{-1}\right) / \mathrm{IFN}-\gamma(100$ units per $\mathrm{mL})$ for $8 \mathrm{~h}$. The LPS/IFN- $\gamma$-treated HCASMCs showed more ROS production compared to untreated cells $(n=3)$. 

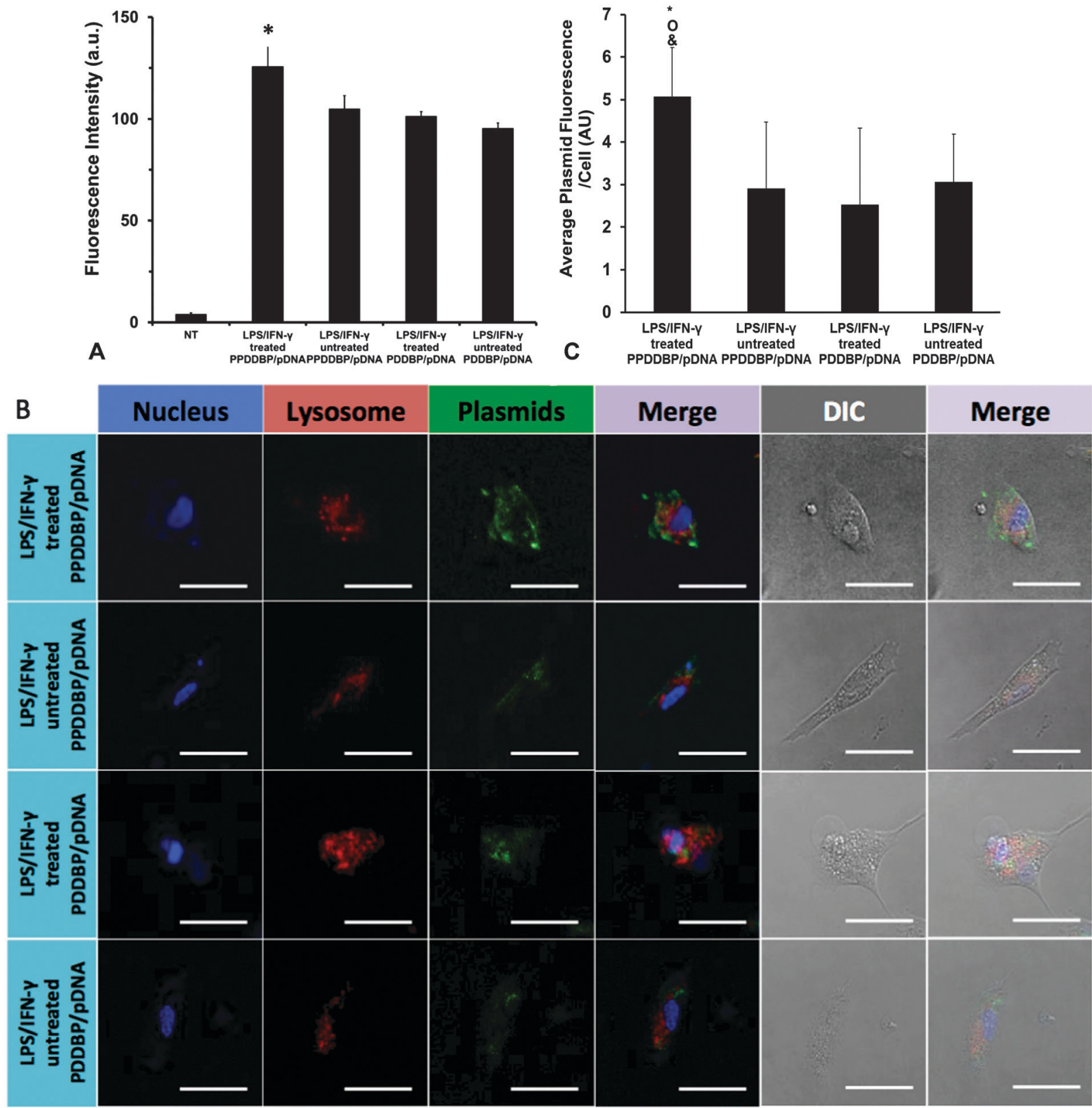

Fig. 7 Cellular uptake of polyplexes prepared using either PPDDBP or non-cleavable PDDBP with fluorescein-labeled pDNA was assessed in HCASMCs after $6 \mathrm{~h}$ incubation in the presence or the absence of LPS/IFN- $\gamma$. (A) Flow cytometry analysis indicates enhanced internalization of LPS /IFN- $\gamma$ treated PPDDBP/pDNA polyplexes compared to other treatment groups. NT represents the non-treated group. ${ }^{*} p<0.05$, where * is in comparison to the other test groups. (B) Confocal images of internalized polyplexes demonstrated distribution of plasmid (green), endosomes (red), and nuclei (blue). The cells were stained with DAPI and endosomal dye Lysotracker to visualize the nucleus and endosomes, respectively. Scale bar: $50 \mu \mathrm{m}$. (C) Confocal image analysis of polyplexes supports that LPS/IFN $-\gamma$ treated PPDDBP/pDNA condition enhance uptake of plasmids significantly compared to all three other conditions. *, $\mathrm{o}, \&$ indicates $p<0.05$, where * is in comparison to LPS/IFN- $\gamma$ untreated PPDDBP/pDNA, o to LPS/IFN- $\gamma$ treated PDDBP/pDNA, and $\&$ to LPS/IFN- $\gamma$ treated PPDDBP/pDNA, with $N=10-15$ cells in each condition.

$\mathrm{ESI}, \dagger$ a complete retention of pDNA within polyplexes was observed whereas free pDNA degraded in the presence of serum. In another gel experiment, protection of pDNA from serum-derived DNAses by PPDDBP was accessed by addition of $1 \%$ SDS to release pDNA from polyplexes in incubation with $50 \%$ serum. Notably, a solution of SDS $(1 \% \mathrm{w} / \mathrm{v})$ solution in PBS was added to each sample to release the pDNA from polyplexes. The appearance of released pDNA bands with persistent intensity relative to free pDNA in PBS indicates PPDDBP completely protected pDNA from FBS-derived DNAses at $37{ }^{\circ} \mathrm{C}$ (Fig. S9, ESI $\dagger$ ).

A major barrier to intracellular gene delivery is entrapment and degradation of polyplexes in the endo-lysosomal pathway. ${ }^{44}$ To test if our nanocarrier can overcome this hurdle, hemolysis of the nanocarrier before and after polyplex formation was evaluated with three different polymer concentrations $\left(1,5\right.$, and $\left.40 \mu \mathrm{g} \mathrm{mL} \mathrm{m}^{-1}\right)$ at four different $\mathrm{pH}$ conditions (7.4. 6.8, 6.2 and 5.8) that mimic 
extracellular and endo-lysosomal trafficking. ${ }^{23}$ As shown in Fig. S10, ESI, $\dagger$ minimal hemolysis of RBCs was observed for all test concentrations at $\mathrm{pH} 7.4$ compared to Triton-X-100 (positive control) indicating excellent hemocompatibility of PPDDBP under physiological conditions. Both polymers alone (Fig. S10A, ESI $\dagger$ ) and polyplexes (Fig. S10B, ESI $\dagger$ ) increased hemolysis of RBCs as $\mathrm{pH}$ decreased from 7.4 to 5.8. This result indicates that polyplexes can rupture $\mathrm{RBC}$ membranes at endosomal $\mathrm{pH}$, thereby enabling successful escape from endo-lysosomal degradation.

\subsection{Cytotoxicity assay}

Cytotoxicity is a major limitation of liposomes, the most widely accepted delivery platform. Therefore, cytocompatibility of polyplexes prepared at different N/P ratios $(1,2,4,8,10$ and 20) with HCASMCs was evaluated by resazurin assay (Fig. 5). ${ }^{36}$ Cells showed more than $85 \%$ cell viability with $\mathrm{PPDDBP}$ polyplexes (N/P ratio at and below 10) while lipofectamine 2000 (LF2K) exhibited significantly lower cell viability. This result suggests better cytocompatibility of PPDDBP/pDNA polyplexes compared to commercial LF2K polyplexes under similar environments.

\subsection{Measurement of intracellular ROS production in HCASMCs}

ROS are overproduced when VSMCs become dysfunctional under pathological vascular environments. Thus, ROS overproduction is likely an effective pathological stimulus for triggering therapeutic release from delivery systems. ${ }^{9}$ To generate an in vitro model of oxidative stress, ROS production of HCASMCs was induced by treatment of LPS $\left(1 \mu \mathrm{g} \mathrm{mL}{ }^{-1}\right)$ and IFN- $\gamma$ (100 units per $\mathrm{mL}$ ) for $6 \mathrm{~h}^{.25}$ Intracellular ROS production was then measured by $\mathrm{CM}-\mathrm{H}_{2}$ DCFDA staining with flow cytometric analysis. ${ }^{37}$ LPS/IFN- $\gamma$-treated HCASMCs showed a significant shift in the mean fluorescence intensity of intracellular CM- $\mathrm{H}_{2}$ DCFDA when compared with untreated HCASMCs (Fig. 6). These conditions were used to test ROS-responsive pDNA transfection of polyplexes.

\subsection{Cellular uptake of polyplexes}

To test if $\mathrm{CP}_{5} \mathrm{~K}$ cleavage in an ROS-rich environment would improve nanoparticle uptake and subsequent transfection, cellular uptake of polyplexes prepared by condensation of fluorescein-labeled pDNA either with ROS-cleavable PPDDBP or control PDDBP was quantitatively determined by flow cytometry (Fig. 7A) LPS/IFN- $\gamma$-treated HCASMCs showed improved uptake of PPDDBP polyplexes when compared to untreated HCASMCs or PDDBP conditions. This result suggests that ROS overproduction of HCASMCs in response to LPS/IFN- $\gamma$ treatment induced dePEGylation of PPDDBP through $\mathrm{CP}_{5} \mathrm{~K}$ peptide and thereby resulted in exposure of cationic PDMAEMA. These processes improved cellular uptake. Confocal microscopy images (Fig. 7B) and quantitative image analysis (Fig. 7C) showed that pDNA (green) was sequestered to endosomes (red) for untreated HCASMCs with PPDDBP, or with either control PDDBP condition, as evidenced by colocalization of the two colors. In stark contrast, treated HCASMCs with

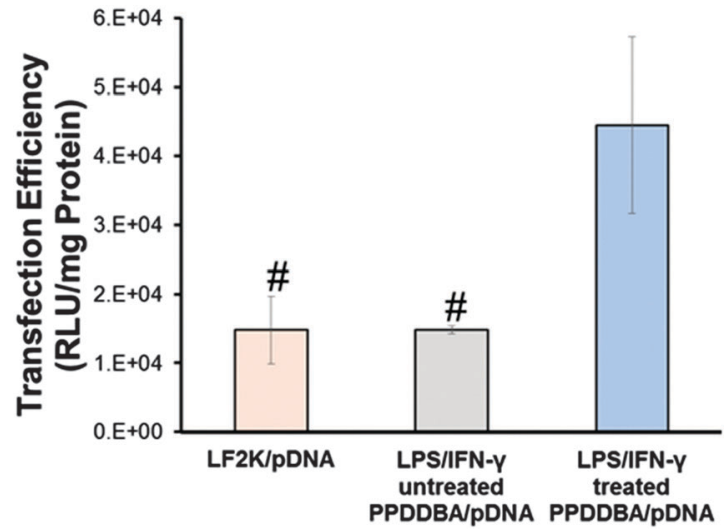

Fig. 8 Transfection efficiency of polyplexes was assessed in HCASMCs using PPDDBP or LF2K containing luciferase pDNA. Luminescence produced by cells post transfection was normalized to total protein. Data are expressed as mean \pm SD $(n=3),{ }^{*} p<0.05$ compared with LPS/IFN- $\gamma$ untreated PPDDBP/pDNA polyplexes.

PPDDBP exhibited free pDNA within the cell, indicating that the $\mathrm{pH}$-responsive nature of the underlying polyplex core was active once dePEGylation occurred, thereby enabling lysosomal escape of polyplexes.

\subsection{In vitro gene transfection}

Transfection efficiency of PPDDBP/pDNA polyplexes with and without LPS/IFN- $\gamma$ treatment was further evaluated in HCASMCs using a luciferase reporter (Fig. 8). PPDDBP polyplexes (N/P 10) were compared with commercially available lipofectamine (LF2K) as a positive control. The transfection efficiency of PPDDBP polyplexes was about 2.5 fold higher in HCASMCS pretreated with LPS/IFN- $\gamma$ than that of untreated HCASMCS or commercially-available LF2K. The excellent cytocompatibility and higher cellular uptake of polyplexes under ROS-rich environments contributed to high transfection efficiency in HCASMCs when treated with LPS/IFN- $\gamma$.

\section{Conclusions}

In summary, the present study demonstrates the use of a new ROS-responsive polyplex nanocarrier as a non-viral gene delivery platform for targeting pathological vascular microenvironments that exhibit high levels of oxidative stress. A dual ROS and pH-responsive polyplex nanocarrier was synthesized by a combination of site-specific orthogonal bio-conjugation and RAFT polymerization methods, and was characterized for use in gene delivery applications. ROS-mediated dePEGylation of the polyplex nanocarrier was confirmed by the increase in $\zeta$-potential in DLS and the appearance of a PEG shoulder in the GPC chromatogram. The polyplexes were shown to maintain hemolytic capability at endosomal $\mathrm{pH}$ and to protect pDNA from DNAses at a high serum concentration. When ROS was overproduced in HCASMCs in response to LPS/IFN- $\gamma$ treatment, higher cellular uptake of polyplexes and enhanced transfection of pDNA were observed, compared with the controls. The collective data suggests the functional significance of this polyplex nanocarrier 
as a new class of dual stimuli-responsive polyplex platform for intravascular gene delivery.

\section{Acknowledgements}

This research work was funded and supported by NSF CAREER CBET 1056046 and NIH UH2 TR000491. DLS and TEM measurements were conducted through the use of the core facilities of the Vanderbilt Institute of Nanoscale Sciences and Engineering (VINSE), which was supported by NSF EPS 1004083.

\section{References}

1 S. Theoharis, M. Manunta and P. H. Tan, Expert Opin. Biol. Ther., 2007, 7, 627-643.

2 M. A. Kay, J. C. Glorioso and L. Naldini, Nat. Med., 2001, 7, 33-40.

3 C. E. Thomas, A. Ehrhardt and M. A. Kay, Nat. Rev. Genet., 2003, 4, 346-358.

4 Z. Liu, Z. Zhang, C. Zhou and Y. Jiao, Prog. Polym. Sci., 2010, 35, 1144-1162.

5 H. Yin, R. L. Kanasty, A. A. Eltoukhy, A. J. Vegas, J. R. Dorkin and D. G. Anderson, Nat. Rev. Genet., 2014, 15, 541-555.

6 L. Brito, S. Little, R. Langer and M. Amiji, Biomacromolecules, 2008, 9, 1179-1187.

7 A. Golda, J. Pelisek, R. Klocke, M. G. Engelmann, P. H. Rolland, C. Mekkaoui and S. Nikol, J. Vasc. Res., 2007, 44, 273-282.

8 C. de Gracia Lux, S. Joshi-Barr, T. Nguyen, E. Mahmoud, E. Schopf, N. Fomina and A. Almutairi, J. Am. Chem. Soc., 2012, 134, 15758-15764.

9 R. E. Clempus and K. K. Griendling, Cardiovasc. Res., 2006, 71, 216-225.

10 N. R. Madamanchi, A. Vendrov and M. S. Runge, Arterioscler., Thromb., Vasc. Biol., 2005, 25, 29-38.

11 H. Cai and D. G. Harrison, Circ. Res., 2000, 87, 840-844.

12 M. S. Shim and Y. Xia, Angew. Chem., Int. Ed., 2013, 52, 6926-6929.

13 C. H. Jones, C.-K. Chen, A. Ravikrishnan, S. Rane and B. A. Pfeifer, Mol. Pharmaceutics, 2013, 10, 4082-4098.

14 K. K. Griendling, D. Sorescu and M. Ushio-Fukai, Circ. Res., 2000, 86, 494-501.

15 J.-C. Tardif, J. Grégoire and P. L’Allier, Am. J. Cardiovasc. Drugs, 2002, 2, 323-334.

16 J. R. Martin, M. K. Gupta, J. M. Page, F. Yu, J. M. Davidson, S. A. Guelcher and C. L. Duvall, Biomaterials, 2014, 35, 3766-3776.

17 S. H. Lee, M. K. Gupta, J. B. Bang, H. Bae and H.-J. Sung, Adv. Healthcare Mater., 2013, 2, 908-915.

18 S. Joshi-Barr, C. de Gracia Lux, E. Mahmoud and A. Almutairi, Antioxid. Redox Signaling, 2014, 21, 730-754.

19 C.-C. Song, F.-S. Du and Z.-C. Li, J. Mater. Chem. B, 2014, 2, 3413-3426.

20 J. Li, Z. Ge and S. Liu, Chem. Commun., 2013, 49, 6974-6976.
21 H. Li, S. S. Yu, M. Miteva, C. E. Nelson, T. Werfel, T. D. Giorgio and C. L. Duvall, Adv. Funct. Mater., 2013, 23, 3040-3052.

22 S. Nie, Nanomedicine, 2010, 5, 523-528.

23 B. C. Evans, C. E. Nelson, S. S. Yu, K. R. Beavers, A. J. Kim, H. Li, H. M. Nelson, T. D. Giorgio and C. L. Duvall, J. Visualized Exp., 2013, 73, e50166.

24 X. Cai, C. Dong, H. Dong, G. Wang, G. M. Pauletti, X. Pan, H. Wen, I. Mehl, Y. Li and D. Shi, Biomacromolecules, 2012, 13, 1024-1034.

25 S. S. Yu, R. L. Koblin, A. L. Zachman, D. S. Perrien, L. H. Hofmeister, T. D. Giorgio and H.-J. Sung, Biomacromolecules, 2011, 12, 4357-4366.

26 E. R. Stadtman and R. L. Levine, Amino Acids, 2003, 25, 207-218.

27 S. H. Lee, T. C. Boire, J. B. Lee, M. K. Gupta, A. L. Zachman, R. Rath and H.-J. Sung, J. Mater. Chem. B, 2014, 2, 7109-7113.

28 S. Agarwal, Y. Zhang, S. Maji and A. Greiner, Mater. Today, 2012, 15, 388-393.

29 A. J. Convertine, D. S. W. Benoit, C. L. Duvall, A. S. Hoffman and P. S. Stayton, J. Controlled Release, 2009, 133, 221-229.

30 T. Goloub, A. de Keizer and M. A. Cohen Stuart, Macromolecules, 1999, 32, 8441-8446.

31 C. E. Nelson, M. K. Gupta, E. J. Adolph, J. M. Shannon, S. A. Guelcher and C. L. Duvall, Biomaterials, 2012, 33, 1154-1161.

32 C. E. Nelson, A. J. Kim, E. J. Adolph, M. K. Gupta, F. Yu, K. M. Hocking, J. M. Davidson, S. A. Guelcher and C. L. Duvall, $A d v$. Mater., 2014, 26, 607-614.

33 D. A. Tirrel and M. Ferrito, Macromol. Synth., 1992, 11, 59-62.

34 C. E. Nelson, J. R. Kintzing, A. Hanna, J. M. Shannon, M. K. Gupta and C. L. Duvall, ACS Nano, 2013, 7, 8870-8880.

35 M. K. Gupta, T. A. Meyer, C. E. Nelson and C. L. Duvall, J. Controlled Release, 2012, 162, 591-598.

36 J. O'Brien, I. Wilson, T. Orton and F. Pognan, Eur. J. Biochem., 2000, 267, 5421-5426.

37 E. Eruslanov and S. Kusmartsev, in Advanced Protocols in Oxidative Stress II, ed. D. Armstrong, Humana Press, 2010, ch. 4, vol. 594, pp. 57-72.

38 N. Kuzkaya, N. Weissmann, D. G. Harrison and S. Dikalov, Biochem. Pharmacol., 2005, 70, 343-354.

39 N. Hogg, V. M. Darley-Usmar, M. T. Wilson and S. Moncada, Biochem. J., 1992, 281, 419-424.

40 T. Merdan, J. Kopeček and T. Kissel, Adv. Drug Delivery Rev., 2002, 54, 715-758.

41 H. Cabral, Y. Matsumoto, K. Mizuno, Q. Chen, M. Murakami, M. Kimura, Y. Terada, M. R. Kano, K. Miyazono, M. Uesaka, N. Nishiyama and K. Kataoka, Nat. Nanotechnol., 2011, 6, 815-823.

42 S. Takae, K. Miyata, M. Oba, T. Ishii, N. Nishiyama, K. Itaka, Y. Yamasaki, H. Koyama and K. Kataoka, J. Am. Chem. Soc., 2008, 130, 6001-6009.

43 D. Putnam, Nat. Mater., 2006, 5, 439-451.

44 B. Layek and J. Singh, Biomacromolecules, 2013, 14, 485-494. 